\title{
Cyclodextrin functionalized poly(methyl methacrylate) (PMMA) electrospun nanofibers for organic vapors waste treatment
}

\author{
Tamer Uyar ${ }^{\mathrm{a}, \mathrm{b}, *}$, Rasmus Havelund ${ }^{\mathrm{a}}$, Yusuf Nur ${ }^{\mathrm{d}}$, Abidin Balan ${ }^{\mathrm{d}}$, Jale Hacaloglu ${ }^{\mathrm{d}}$, Levent Toppare ${ }^{\mathrm{d}}$, \\ Flemming Besenbacher ${ }^{\mathrm{a}, \mathrm{c}}$, Peter Kingshott ${ }^{\mathrm{a}}$ \\ a Interdisciplinary Nanoscience Center (iNANO), Aarhus University, DK-8000 Aarhus C, Denmark \\ ${ }^{\mathrm{b}}$ UNAM-Institute of Materials Science E Nanotechnology, Bilkent University, Ankara 06800, Turkey \\ c Department of Physics and Astronomy, University of Aarhus, DK-8000 Aarhus C, Denmark \\ d Department of Chemistry, Middle East Technical University, Ankara 06530, Turkey
}

\section{A R T I C L E I N F O}

\section{Article history:}

Received 3 August 2010

Received in revised form

17 September 2010

Accepted 19 September 2010

Available online 25 September 2010

\section{Keywords:}

Electrospinning

Cyclodextrin

Poly(methyl methacrylate) (PMMA)

Nanofilter

Nanofiber

\begin{abstract}
A B S T R A C T
Poly(methyl methacrylate) (PMMA) nanofibers containing the inclusion complex forming betacyclodextrin $(\beta-C D)$ were successfully produced by means of electrospinning in order to develop functional nanofibrous webs for organic vapor waste treatment. Electrospinning of uniform PMMA nanofibers containing different loadings of $\beta-C D(10 \%, 25 \%$ and $50 \%(w / w))$ was achieved. The surface sensitive spectroscopic techniques; X-ray photoelectron spectroscopy (XPS) and time-of-flight secondary ion mass spectrometry (ToF-SIMS) showed that some of the $\beta-C D$ molecules are present on the surface of the PMMA nanofibers, which is essential for the trapping of organic vapors by inclusion complexation. Direct pyrolysis mass spectrometry (DP-MS) studies showed that PMMA nanowebs containing $\beta-C D$ can entrap organic vapors such as aniline, styrene and toluene from the surroundings due to inclusion complexation with $\beta-C D$ that is present on the fiber surface. Our study showed that electrospun nanowebs functionalized with cyclodextrins may have the potential to be used as molecular filters and/or nanofilters for the treatment of organic vapor waste and air filtration purposes.
\end{abstract}

(C) 2010 Elsevier B.V. All rights reserved.

\section{Introduction}

Electrospinning is a cost-effective and versatile technique for the production of nanofibers/nanowebs. Electrospun nanofibers/nanowebs have several distinctive characteristics including very large surface area to volume ratio, nanoporous structure, and have unique physical performance along with the design flexibility for chemical/physical functionalization [1-4]. It has been shown that the electrospun nanofibers/nanowebs are very applicable in the field of filtration since such nanowebs can filter tiny particles as well as molecules and have significantly high adsorptive capacity due to their high surface area and nanoporous structure [5-8].

Cyclodextrins (CD) are cyclic oligosaccharides consisting of $\alpha(1,4)$-linked glucopyranose units with a toroid-shaped molecular structure (Fig. 1). Due to their unique chemical structure, CDs can

\footnotetext{
* Corresponding author at: UNAM-Institute of Materials Science \& Nanotechnology, Bilkent University, Ankara 06800, Turkey. Tel.: +90 312 2903571; fax: +90 3122664365 .

E-mail addresses: tamer@unam.bilkent.edu.tr, tameruyar@gmail.com, tamer@inano.dk (T. Uyar).
}

form non-covalent host-guest inclusion complexes (CD-IC) with various molecules by including them inside their cavity [9-10]. The formation and the stability of the CD-ICs depend on many factors such as the size/shape match and the binding forces between the $\mathrm{CD}$ host and the guest molecules [11-12]. It has been shown that cyclodextrins and cyclodextrin functionalized materials have the potential to be used in filters and membranes for separation, purification and filtration purposes since they have the ability to form inclusion complexes with hazardous chemicals and polluting substances [13-16].

The functionalization of nanofibers/nanowebs with cyclodextrins (CD) is extremely interesting since such nanofibers/nanowebs containing CD molecules can potentially act as an efficient molecular filter by combining the specific complex formation with organic compounds with the very high surface area of the nanoweb [7,17-18]. In our very recent studies, we have shown that electrospun polystyrene (PS) nanowebs incorporating CDs can filter organic molecules (e.g., phenolphthalein) from solution by inclusion complexation $[7,18]$. In the present study, by means of electrospinning we produced $\beta-C D$ functionalized poly(methyl methacrylate) (PMMA) nanofibrous webs by taking advantage of the high surface-volume ratio of nanofibers to form molecular filters and/or nanofilters with the added advantage of having $C D$ 


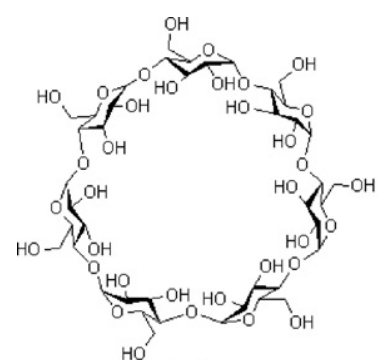

(a)

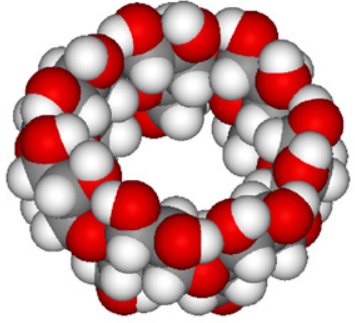

(b)

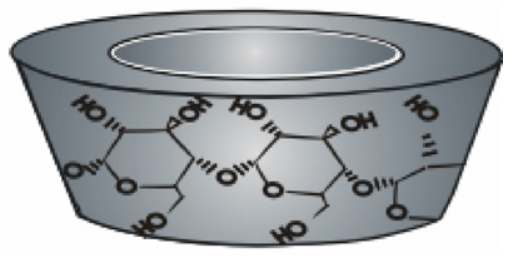

(c)

Fig. 1. (a) Chemical structure of $\beta-C D$, (b) 3-D structure of $\beta-C D$ (c) schematic representation of toroid-shaped molecular structure of $\beta$-CD.

as a functional additive aiming at trapping organic waste vapors from the surroundings for air filtration purposes. Our results demonstrated that the PMMA $\beta-C D$ nanowebs were successful in capturing the organic molecules (e.g., styrene, aniline and toluene) from the vapor phase.

\section{Experimental}

\subsection{Materials}

Amorphous poly(methyl methacrylate) (PMMA) $\left(\mathrm{M}_{\mathrm{w}} \sim 350,000\right.$, Aldrich), N,N-dimethylformamide (DMF) (Fluka, 98\%), toluene (Carlo Erba, \%99.5), aniline (Riedel- de Haen, \%99.5), styrene (Acros Organics, 99\%) and beta-cyclodextrin ( $\beta-C D$ ) (obtained from Wacker Chemie AG, Germany) were used as-received without any further purification.

\subsection{Electrospinning}

The electrospinning of bead-free uniform PMMA/ $\beta-C D$ nanofibers was reported in our previous study [19]. In brief, the homogeneous solutions were prepared by dissolving PMMA and $\beta-C D$ in DMF; the PMMA concentration was $10 \%(w / v)$ and the $\beta-C D$ was $10 \%, 25 \%$ and $50 \%(w / w)$ with respect to PMMA. The concentration of the PMMA solution without any CD was $15 \%$ $(\mathrm{w} / \mathrm{v})$. The electrospinning parameters were as follows; feed rate of polymer solution was $1 \mathrm{~mL} / \mathrm{h}$, the applied voltage was $15 \mathrm{kV}$ and the tip-to-collector distance was $10 \mathrm{~cm}$. The collected nanowebs were dried at $40^{\circ} \mathrm{C}$ under vacuum oven for $24 \mathrm{~h}$ to remove the residual solvent (DMF).

\subsection{Characterization and measurements}

\subsubsection{Scanning electron microscopy (SEM)}

The morphology of the nanofibers was explored by highresolution scanning electron microscopy (SEM) (FEI, Nova 600 NanoSEM and Quanta 200 FEG). The average fiber diameter was determined from the SEM images and around 100 fibers were analyzed to calculate the average fiber diameter.
2.3.2. Surface characterization: $X$-ray photoelectron spectroscopy (XPS) and time-of-flight secondary ion mass spectrometry (ToF-SIMS)

X-ray photoelectron spectroscopy (XPS) measurements on the nanofibrous webs were carried out using a Kratos AXIS Ultra ${ }^{\text {DLD }}$, using a monochromatic $\mathrm{Al}_{\mathrm{K}, \alpha}$ source $(1486.6 \mathrm{eV}$ ) operating at $10 \mathrm{kV}$ and $15 \mathrm{~mA}$. The nanofiber samples that were analyzed were cut from the electrospinning collector plate consisting of $\mathrm{Al}$ foil containing a homogeneous and thick fibrous web. The analysis area was approximately $300 \mu \mathrm{m} \times 700 \mu \mathrm{m}$. At least 3 spots on 5 replicates of each sample type were analyzed. The Kratos charge neutralizer system was used on all samples, and sample charging effects on the measured binding energy positions were corrected by referencing the lowest binding energy component of the $\mathrm{C} 1 \mathrm{~s}$ spectral envelope to $285.0 \mathrm{eV}$, corresponding to the $\mathrm{C}-\mathrm{C} / \mathrm{C}-\mathrm{H}$ species. For each sample, a take-off angle (TOA) of $90^{\circ}$ (with respect to the sample surface) was used allowing a maximum probe depth of $10 \mathrm{~nm}$. Wide energy survey scans (WESS) were obtained over the range $0-1200 \mathrm{eV}$ binding energy at a detector pass energy of $160 \mathrm{eV}$, and used to determine the surface elemental composition. Highresolution spectra were recorded for the $\mathrm{C} 1 \mathrm{~s}$ region at pass energy of $10 \mathrm{eV}$. Deconvolution of the high-resolution region was performed by subtraction of a linear background and application of a mixed Gaussian-Lorentzian synthetic peak.

Time-of-flight secondary ion mass spectrometry (ToF-SIMS) spectra were acquired with an ION-TOF TOF.SIMS 5 using a $25 \mathrm{keV}$ bunched $\mathrm{Bi}_{3}{ }^{+}$primary ions with a target current of $0.3 \mathrm{pA}$. As for $\mathrm{XPS}$, fiber mats on $\mathrm{Al}$ foil were analyzed, and the analysis area was $100 \mu \mathrm{m} \times 100 \mu \mathrm{m}$. In all cases an electron flood gun was applied for charge compensation, and the primary ions dose was kept below $10^{12}$ ions $/ \mathrm{cm}^{2}$ to stay within the static SIMS regime. Both positive and negative ions spectra were acquired. In the positive polarity, mass calibration of the spectra was based on $\mathrm{CH}_{3}{ }^{+}, \mathrm{C}_{2} \mathrm{H}_{3}{ }^{+}, \mathrm{C}_{2} \mathrm{H}_{5}{ }^{+}$, and $\mathrm{C}_{3} \mathrm{H}_{5}{ }^{+}$ions. In the negative polarity, $\mathrm{C}^{-}, \mathrm{C}_{2}{ }^{-}, \mathrm{C}_{3}{ }^{-}$, and $\mathrm{C}_{4}{ }^{-}$ions were used for calibration.

\subsubsection{Entrapment of organic vapors by $P M M A / \beta-C D$ nanofibrous} webs

PMMA $/ \beta-C D$ nanofibrous webs were tested for trapping styrene, toluene and aniline vapor. $1 \mathrm{~mL}$ of aniline, styrene or toluene was placed on a watch glass and left in glass desiccators for $1 \mathrm{~h}$. After

Table 1

The composition of PMMA $/ \beta-C D$ solutions and the average fiber diameter of the resulting electrospun PMMA and PMMA/ $\beta$-CD nanofibers.

\begin{tabular}{|c|c|c|c|c|}
\hline Solution & $\% \mathrm{PMMA}^{\mathrm{a}}(\mathrm{w} / \mathrm{v})$ & $\% C D^{b}(w / w)$ & Morphology & Average fiber diameter $(\mathrm{nm})$ \\
\hline PMMA & 15 & - & Nanofibers & $977 \pm 88$ \\
\hline PMMA $/ \beta-C D 10$ & 10 & 10 & Nanofibers & $675 \pm 89$ \\
\hline PMMA/ $\beta-C D 25$ & 10 & 25 & Nanofibers & $625 \pm 70$ \\
\hline PMMA $/ \beta-C D 50$ & 10 & 50 & Nanofibers & $816 \pm 77$ \\
\hline
\end{tabular}

a With respect to solvent.

b With respect to polymer (PMMA). 

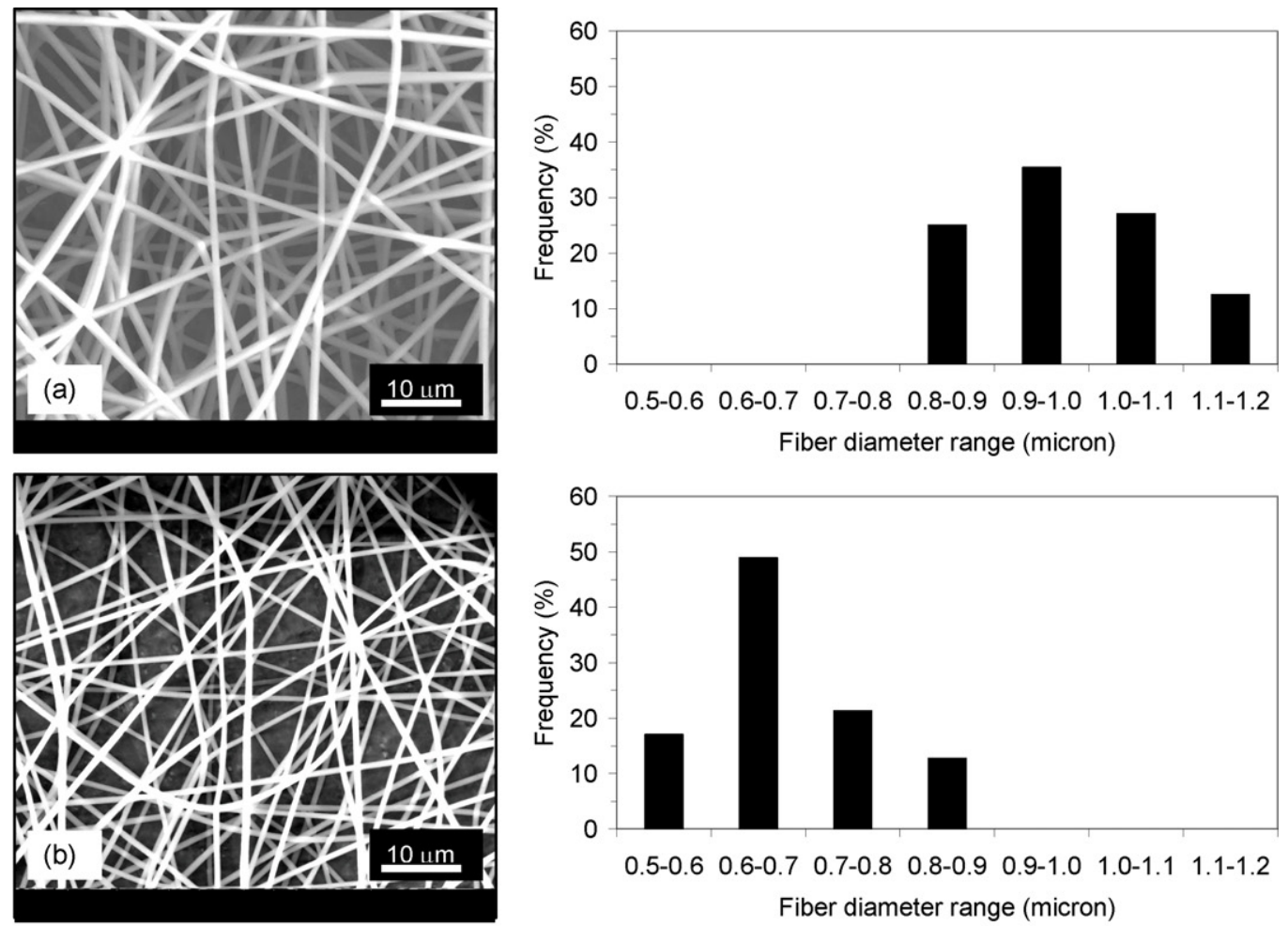

Fiber diameter range (micron)
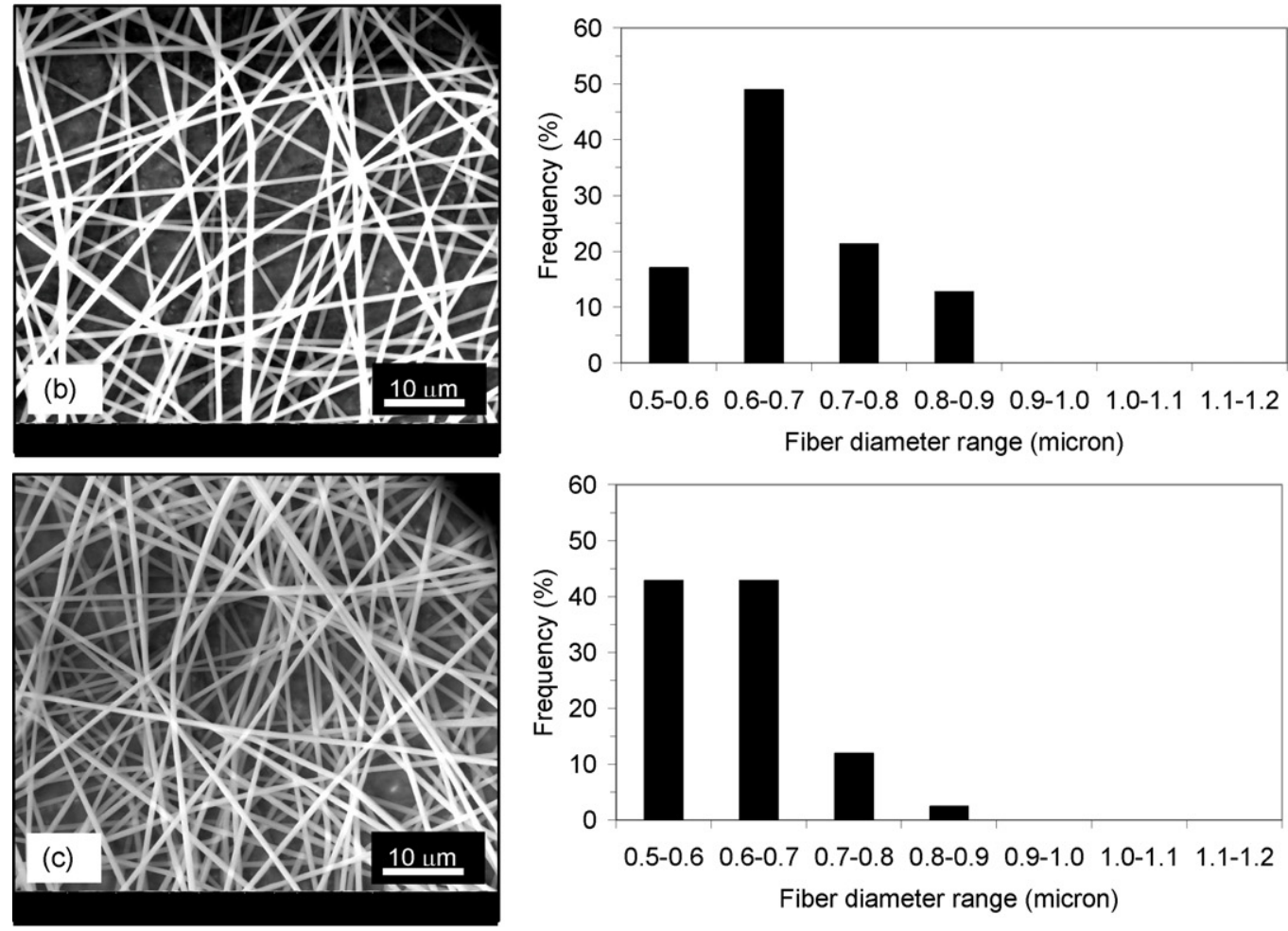

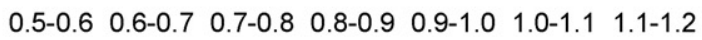

Fiber diameter range (micron)
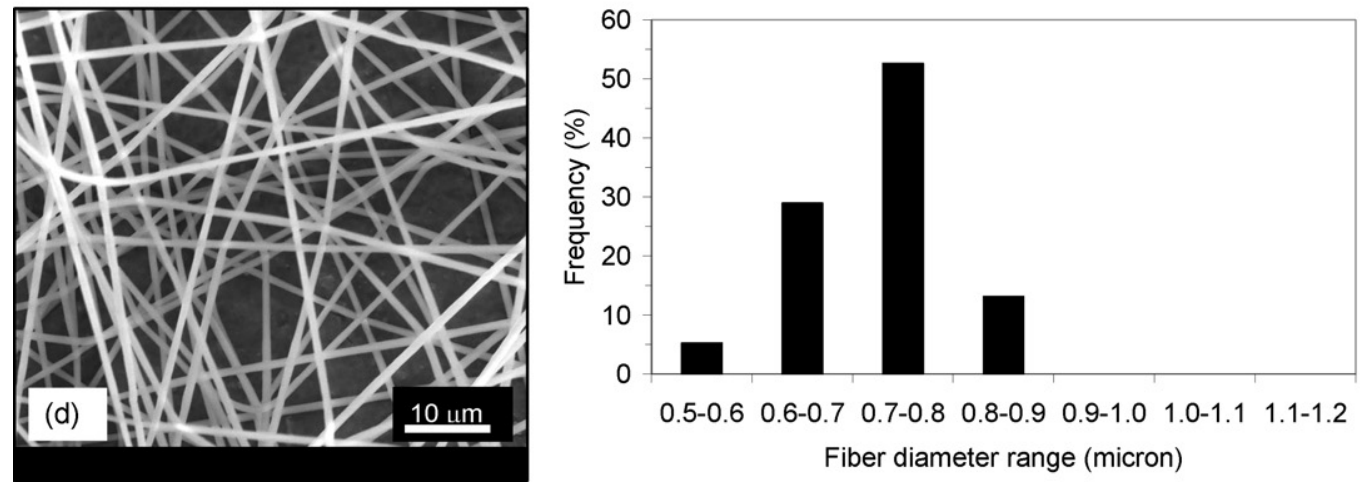

$\begin{array}{lllllll}0.5-0.6 & 0.6-0.7 & 0.7-0.8 & 0.8-0.9 & 0.9-1.0 & 1.0-1.1 & 1.1-1.2\end{array}$

Fiber diameter range (micron)

Fig. 2. SEM images of electrospun nanofibers of (a) PMMA, (b) PMMA/ $\beta-C D 10$, (c) PMMA $/ \beta-C D 25$ and (d) PMMA $/ \beta-C D 50$. The fiber diameter distributions are shown on the right side.

that, 50 mg PMMA/ $\beta-C D$ nanowebs containing different amounts of $\beta-C D(10 \%, 25 \%$ and $50 \%(w / w))$ were placed into the glass desiccators ( $32 \mathrm{~cm}$ (diameter) and $23 \mathrm{~cm}$ (height)), and the desiccators were sealed. The nanowebs (PMMA/ $\beta-C D 10$, PMMA/ $\beta-C D 25$ and PMMA $/ \beta-C D 50)$ were kept in aniline, styrene or toluene atmosphere for 1 or $3 \mathrm{~h}$ in the desiccators. Then, the nanowebs were removed from the desiccators and transferred into the suction hood to evaporate any solvent adsorbed on the nanoweb surface. The nanowebs were kept in the suction hood for a period that was equal to that of the organic vapor trapping process (e.g., $1 \mathrm{~h}$ or $3 \mathrm{~h}$ ) prior to the direct pyrolysis mass spectrometry (DP-MS) analyses.

\subsubsection{Direct pyrolysis mass spectrometry (DP-MS)}

Direct pyrolysis mass spectrometry (DP-MS) system consists of Waters Quattro Micro GC tandem MS with an EI ion source and a mass range of 10-1500 Da coupled with a direct insertion 

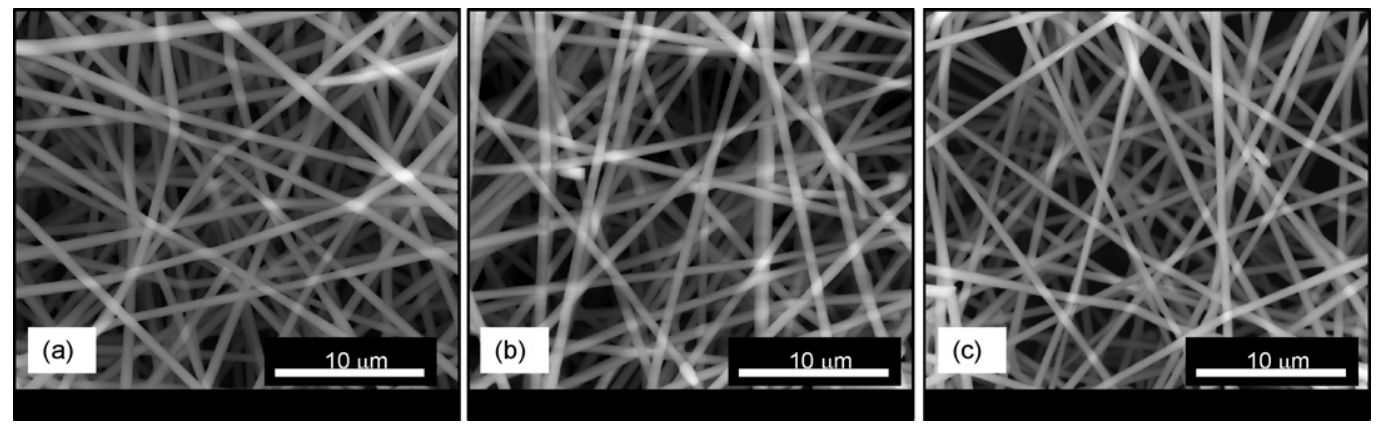

Fig. 3. SEM images of electrospun nanofibers of PMMA/ $\beta-C D 25$ after exposure to $3 \mathrm{~h}$ of (a) aniline, (b) styrene and (c) toluene vapor.

probe $\left(T_{\max }=650^{\circ} \mathrm{C}\right) .0 .01 \mathrm{mg}$ of each nanofibrous web sample was pyrolyzed in flared quartz sample vials. The temperature was increased at a rate of $10^{\circ} \mathrm{C} / \mathrm{min}$, and the scan rate was $1 \mathrm{scans} / \mathrm{s}$, with simultaneous mass spectrometric analysis of the pyrolytic fragments.

\section{Results and discussion}

\subsection{SEM characterization}

The optimization of the electrospinning conditions for producing uniform $\beta$-cyclodextrin containing PMMA nanofibers (PMMA/ $\beta-C D)$ was reported in our previous study [19]. The composition of PMMA/ $\beta-C D$ solutions and the average fiber diameter of the resulting electrospun nanofibers are listed in Table 1 . The representative scanning electron microscopy (SEM) images of the electrospun PMMA and PMMA $/ \beta-C D$ nanofibers (PMMA $/ \beta-C D 10$, PMMA $/ \beta-C D 25$ and PMMA $/ \beta-C D 50)$ containing different amounts of $\beta-C D(10 \%, 25 \%$ and $50 \%(w / w)$ with respect to PMMA) and the fiber diameter distributions are shown in Fig. 2. The diameter of the resulting electrospun PMMA nanofibers are thicker compared to PMMA/ $\beta$-CD nanofibers due to the high viscosity of the solution because only $15 \%(\mathrm{w} / \mathrm{v})$ polymer concentration resulted in bead-free uniform nanofibers whereas $10 \%(\mathrm{w} / \mathrm{v})$ polymer concentration was good enough for PMMA/ $\beta-C D$ systems in order to produce uniform nanofibers. The diameter distribution of PMMA/ $\beta-C D$ nanofibers having different amount of $\beta-C D$ is more or less close to each other without showing any considerable differences except the PMMA $/ \beta-C D 50$ nanofibers are slightly thicker compared to PMMA $/ \beta-C D 10$ and PMMA/ $\beta-C D 25$ nanofibers. The

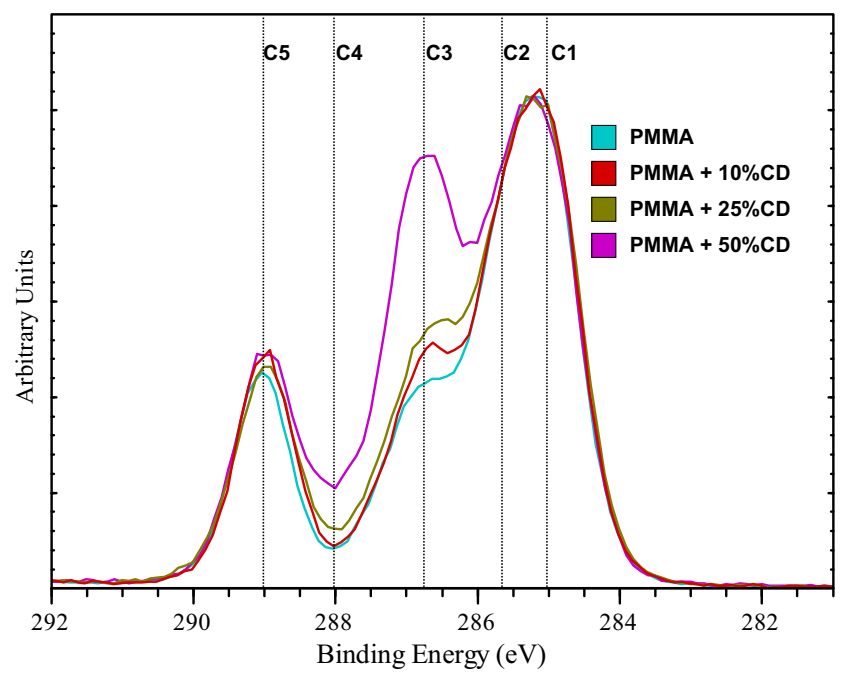

Fig. 4. Overlay of XPS C 1 s spectra of the PMMA and PMMA/ $\beta-C D$ nanowebs.
Table 2

Atomic concentrations of the surface of the $\beta-C D$ and nanowebs of the PMMA and PMMA $/ \beta-C D$ determined from XPS survey spectra.

\begin{tabular}{|c|c|c|c|}
\hline Sample & $C(\%)$ & $\mathrm{O}(\%)$ & \pm \\
\hline$\beta-C D$ & 58.7 & 41.3 & 0.1 \\
\hline PMMA & 74.7 & 25.3 & 0.3 \\
\hline PMMA/ $\beta-C D 10$ & 73.7 & 26.3 & 0.3 \\
\hline PMMA/ $\beta-C D 25$ & 73.4 & 26.6 & 0.3 \\
\hline PMMA/ $\beta-C D 50$ & 70.4 & 29.6 & 0.7 \\
\hline
\end{tabular}

observed small variations in fiber diameters are owing to differences in conductivity and viscosity of the PMMA $/ \beta-C D$ solutions as discussed in our previous report [19]. We also examined the dimension stability of PMMA $/ \beta-C D$ nanowebs after exposure to organic vapors (aniline, styrene and toluene), and we observed that the samples kept their nanofibrous morphology. In Fig. 3, the representative SEM images of PMMA/ $\beta$-CD25 nanowebs after exposure to aniline, styrene or toluene vapor for $3 \mathrm{~h}$ are depicted as an example.

\subsection{Surface characterization: XPS and ToF-SIMS}

XPS and ToF-SIMS were used to study the surface chemistry of the nanofibrous webs and specifically to determine to what extent $\beta-C D$ molecules are present on the surface of the PMMA $/ \beta$ $\mathrm{CD}$ nanofibrous webs prepared by electrospinning. For the $\beta-\mathrm{CD}$
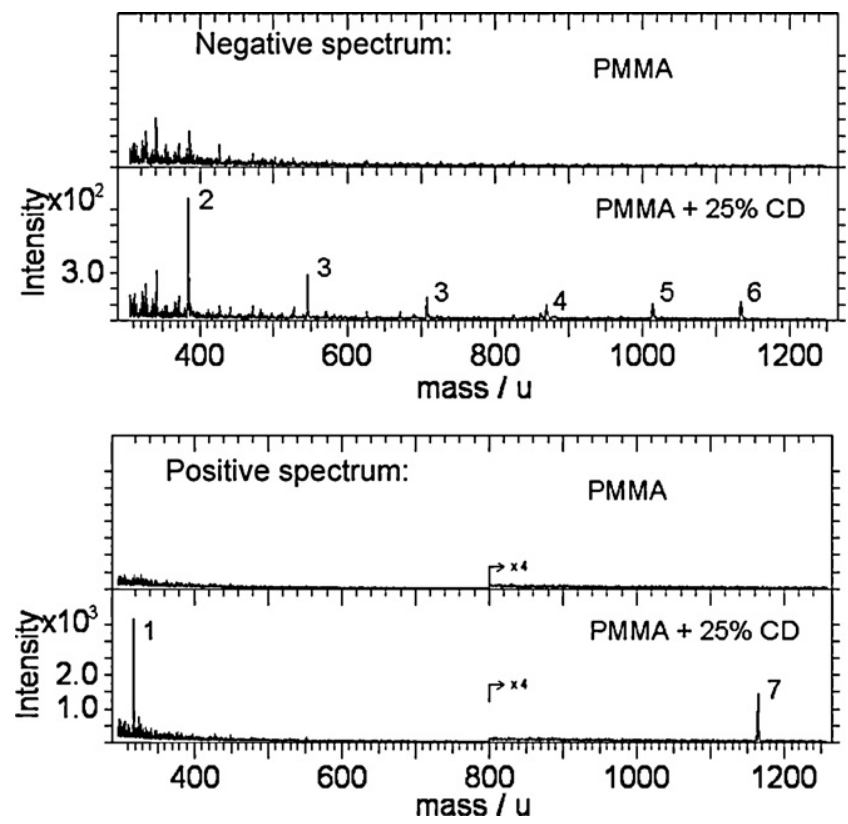

Fig. 5. ToF-SIMS positive and negative ion spectra of PMMA and PMMA/ $\beta-C D 25$ nanowebs. 
Table 3

Peak assignments derived from the TOF-SIMS spectra of PMMA/ $\beta-C D$ nanowebs.

\begin{tabular}{llc}
\hline Peak & Ion & Measured mass $/ \mu$ \\
\hline 1 & $\mathrm{C}_{12} \mathrm{H}_{21} \mathrm{O}_{10^{+}}$ & 325.2 \\
2 & $\mathrm{C}_{14} \mathrm{H}_{23} \mathrm{O}_{12}^{-}$ & 383.2 \\
3 & $\mathrm{C}_{20} \mathrm{H}_{33} \mathrm{O}_{27^{-}}$ & 545.1 \\
4 & $\mathrm{C}_{26} \mathrm{H}_{43} \mathrm{O}_{22}{ }^{-}$ & 707.0 \\
5 & $\mathrm{C}_{32} \mathrm{H}_{53} \mathrm{O}_{27}^{-}$ & 869.3 \\
6 & $\mathrm{C}_{42} \mathrm{H}_{69} \mathrm{O}_{35}^{-}$ & 1013.9 \\
7 & $\mathrm{C}_{42} \mathrm{H}_{70} \mathrm{O}_{35} \mathrm{Na}^{+}$ & 1157.6 \\
\hline
\end{tabular}

molecules to be able to form inclusion complexes with the target molecules in the vapor phase, it is essential that the $\beta$-CD molecules are available on the surface of the nanofibrous webs. Table 2 shows atomic concentrations generated from XPS survey spectra of the PMMA nanofibers with and without $\beta-C D$. Increasing oxygen content in the outer $\sim 10 \mathrm{~nm}$ of the sample is observed with increasing $\beta-C D$ amount used in the electrospinning of nanofibers.

The difference in surface chemistry can be addressed from investigating the high energy resolution XPS spectra of the C1s region in detail. Fig. 4 shows an overlay of the C1s spectra from PMMA and PMMA/ $\beta-C D$ nanowebs. The four $C 1 \mathrm{~s}$ spectra that are normalized to the same intensity at energy $285 \mathrm{eV}$ can be deconvoluted into 5 different components. One component at $285.0 \mathrm{eV}, \mathrm{C} 1$, is assigned to aliphatic carbon, $\mathrm{C}-\mathrm{C} / \mathrm{C}-\mathrm{H}$, which is the major component of pure PMMA, but is also found in low concentrations in spectra from pure $\beta-\mathrm{CD}$. The component $\mathrm{C} 2$ at $285.7 \mathrm{eV}$ is assigned to $\beta$-shifted carbon next to the carbonyl group of PMMA, $C-C=0 . C 3(286.8 \mathrm{eV})$ is a convolution of the ether carbon, $C-\mathrm{O}-\mathrm{C} / \mathrm{O}-\mathrm{C}$, found in both PMMA and $\beta-\mathrm{CD}$ and the $C-\mathrm{OH}$ carbon of $\beta-\mathrm{CD}$. The $\mathrm{C} 4$ peak at $288.0 \mathrm{eV}$ is
$\mathrm{O}-\mathrm{C}-\mathrm{O}$ of $\beta-\mathrm{CD}$, and $\mathrm{C} 5(289.0 \mathrm{eV})$ is from the acrylate bond, $\mathrm{O}-\mathrm{C}=\mathrm{O}$, of PMMA.

The relative concentrations of $\mathrm{C} 3$ and $C 4$ increased with increasing amount of the $\beta-C D$ used in the preparation of $P M M A / \beta-C D$, while the fractions $C 1, C 2$, and $C 5$ decreased. This is in agreement with an increasing $\beta-C D$ concentration on the surface, using the assignments above. Based on these results, the difference in surface chemistry between pure PMMA and PMMA/ $\beta-C D$ nanowebs is explained by the presence of the $\beta-C D$ on the surface of the nanoweb. From the atomic concentrations in Table 2, it is estimated that the $\beta-C D$ concentration of the probed volume is approximately $6 \%, 9 \%$, and $27 \%$ for PMMA $/ \beta-C D 10$, PMMA $/ \beta-C D 25$ and PMMA $/ \beta-C D 50$, respectively. The lower concentrations of $\beta-C D$ on the surface of the nanofibrous webs compared to the composition of the solutions of the electronspun webs indicate that the $\beta-C D$ is not homogeneously distributed throughout the fiber polymer matrix.

Fig. 5 shows a representative example of ToF-SIMS spectra of PMMA and PMMA/ $\beta-C D 25$ nanofibrous webs in the mass range $>300 \mu$. At lower mass range, a few differences are observed between ToF-SIMS spectra of pure PMMA and PMMA/ $\beta-C D 25$ nanowebs. Most notable in the positive ion spectrum is a significantly higher intensity of peaks in the spectrum from PMMA/ $\beta-C D 25$ at $m / z 19.02$ and 31.02, which are assigned to $\mathrm{H}_{3} \mathrm{O}^{+}$and $\mathrm{CH}_{3} \mathrm{O}^{+}$, respectively. The two samples are even more clearly distinguished in the higher mass range. In both the negative and positive spectra, a number of characteristic peaks, which are only observed in the spectrum of PMMA/ $\beta-C D 25$ nanofibers, can be assigned to fragments of $\beta-C D$ molecules and intact $\beta$ $\mathrm{CD}$ molecules. The ions and the peak assignments are listed in

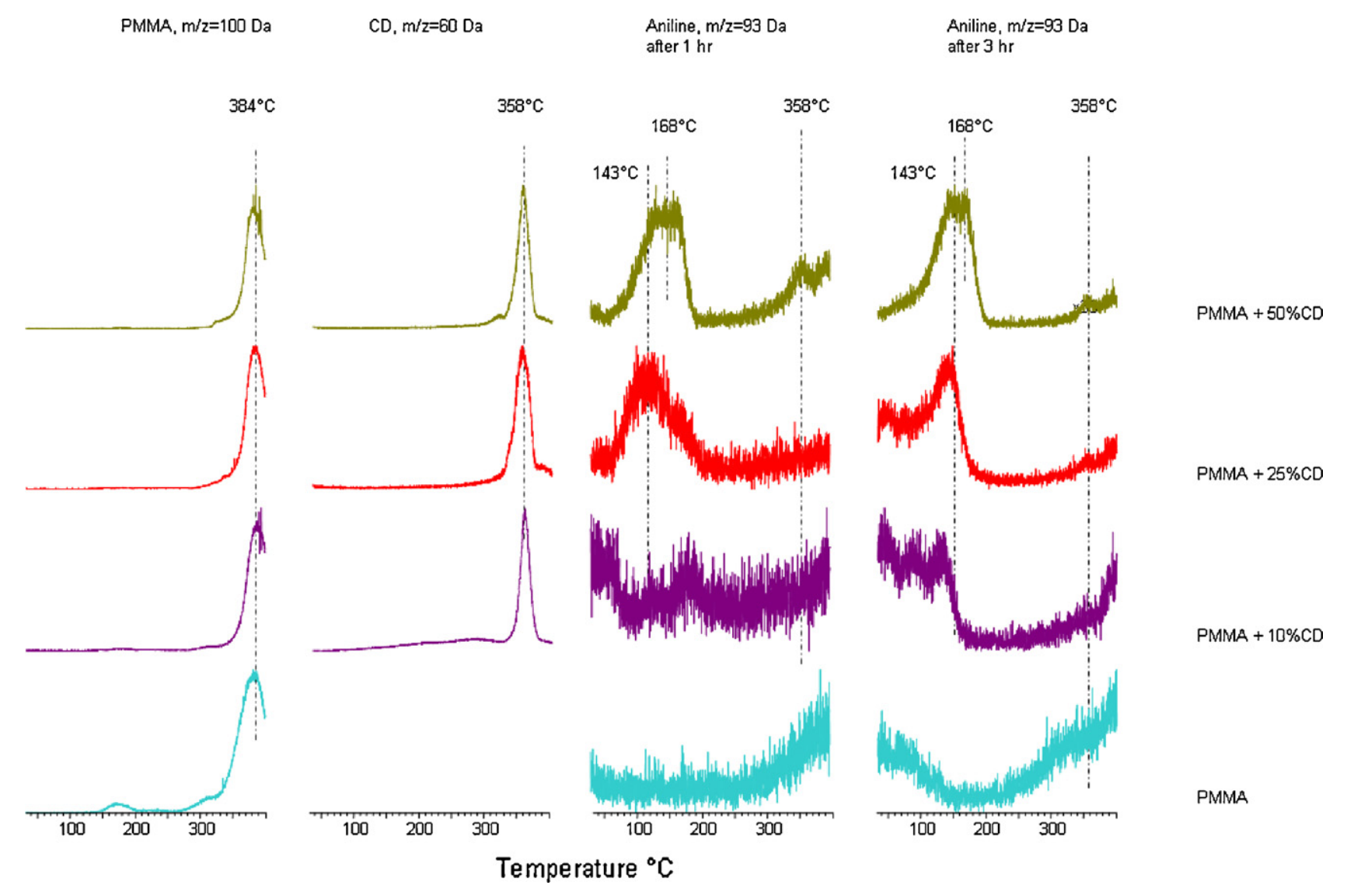

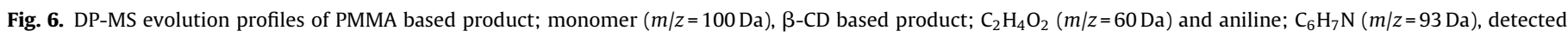

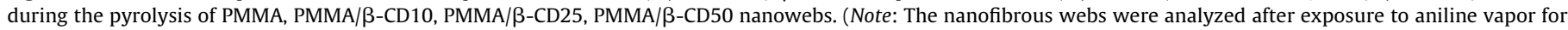
$1 \mathrm{~h}$ and $3 \mathrm{~h}$ ). 
PMMA, $m / z=100 \mathrm{Da}$

$\mathrm{CD}, \mathrm{m} / \mathrm{z}=60 \mathrm{Da}$

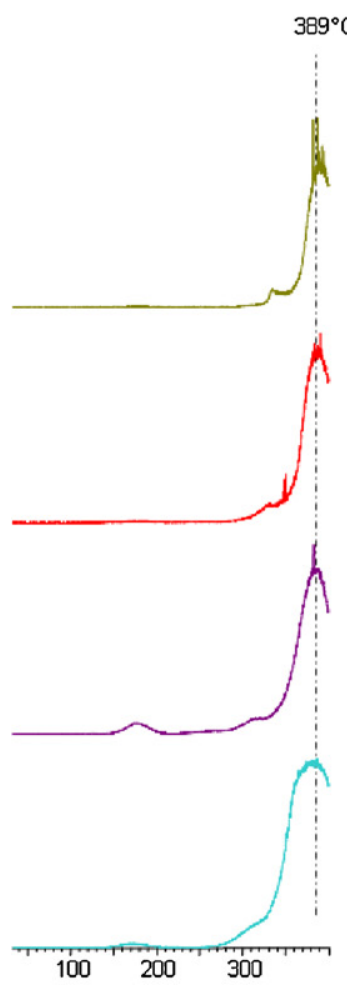

Styrene, $\mathrm{m} / \mathrm{z}=104 \mathrm{Da}$ after $1 \mathrm{hr}$
Styrene, $\mathrm{m} / \mathrm{z}=104 \mathrm{Da}$ after $3 \mathrm{hr}$
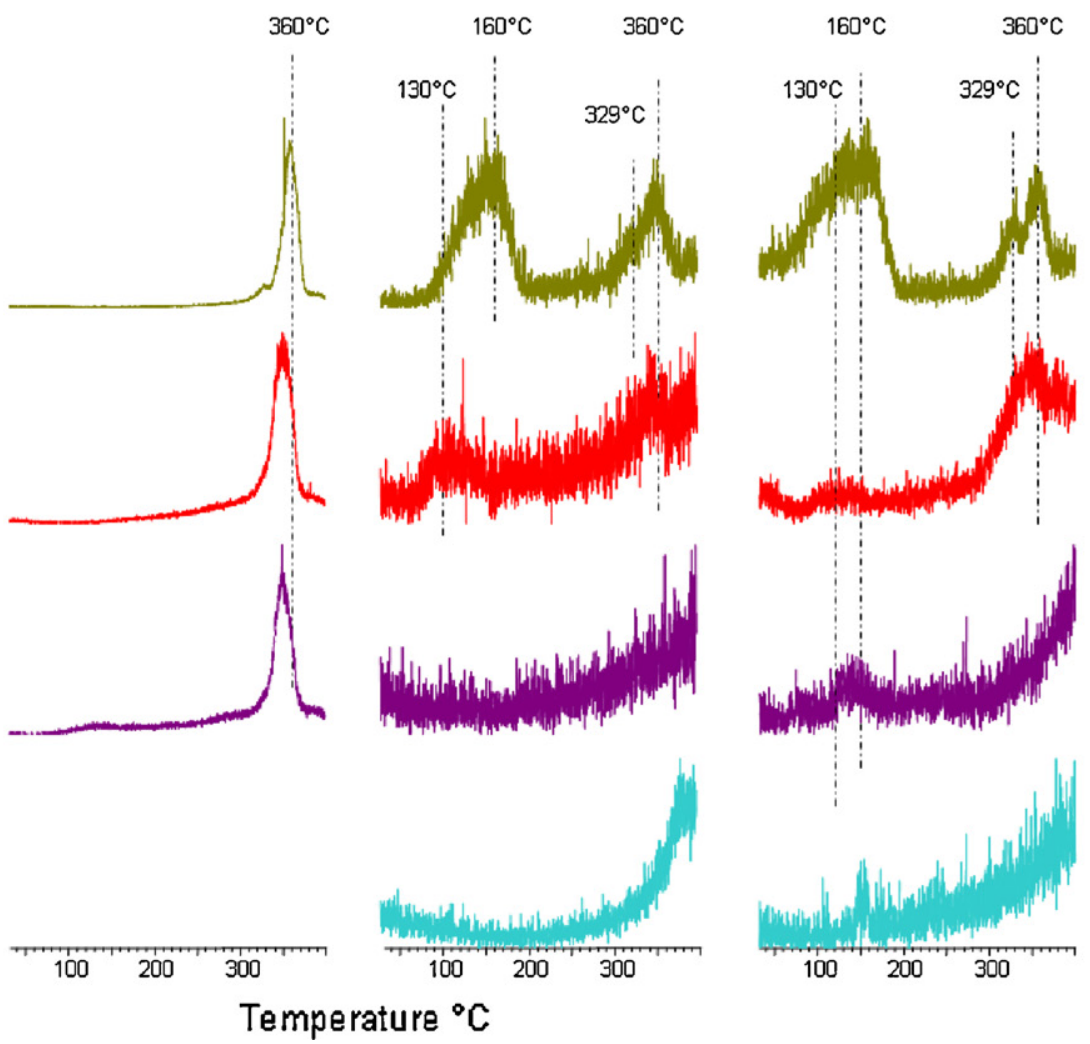

$\mathrm{PMMA}+50 \% \mathrm{CD}$

$\mathrm{PMMA}+25 \% \mathrm{CD}$

PMMA+ $10 \% C D$

PMMA

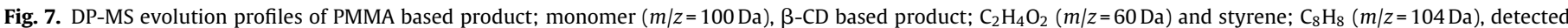

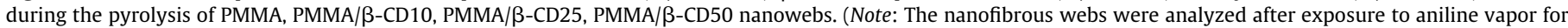
$1 \mathrm{~h}$ and $3 \mathrm{~h}$ ).

Table 3. This fragmentation pattern of $\beta-C D$ is in agreement with previous studies [20-21]. The ToF-SIMS spectra thus confirm that $\beta-C D$ is present on the surface of the nanofibrous webs; however, the outer $1-2 \mathrm{~nm}$ of the surface of the webs mainly consists of PMMA. The PMMA/ $\beta-C D 10$ and PMMA $/ \beta-C D 50$ were also analyzed, and the same peaks were observed for these samples.

\subsection{Direct pyrolysis mass spectrometry}

In order to confirm the inclusion complexation of $\beta-C D$ with organic vapors (aniline, styrene and toluene) and investigate the entrapment capability of the PMMA/ $\beta-C D$ nanowebs, direct pyrolysis mass spectrometry (DP-MS) analyses were performed on the PMMA $/ \beta-C D$ nanowebs after exposure to organic vapors. Once the guest molecule has been included in the host CD cavity, the thermal evaporation/decomposition of the guest molecule shifts to higher temperatures due to the strong interaction with the $C D$ cavity. Therefore, thermal analyses such as thermogravimetric analysis (TGA) and the DP-MS can be a very useful technique to characterize the CD host-guest inclusion complexes [16,22]. In general, DP-MS technique is used to determine the thermal characteristics such as volatility, thermal stability and thermal degradation products of the materials [22-25]. For the multi-component material analyses, DP-MS allows the separation of individual components as a function of their volatilities and/or thermal stabilities. However, pyrolysis mass spectra of a multi-component system, especially the ones involving polymers, are usually very complex due to disso- ciative ionization processes and due to the fact that all fragments with the same mass-to-charge ratio contribute to the intensity of the same peak in the mass spectrum. Thus, in pyrolysis MS analyses, not only the detection of the product, but also the variation of its yield as a function of temperature, the evolution profile, is very important to determine the source of the product.

In order to investigate the entrapment of aniline, styrene and toluene by the PMMA nanowebs containing $10 \%, 25 \%$ and $50 \%$ $\beta-C D$ (PMMA $/ \beta-C D 10$, PMMA $/ \beta-C D 25$ and PMMA $/ \beta-C D 50)$, the evolution profiles of single ion pyrograms of the characteristic PMMA and $\beta-C D$ based products were investigated. In particular the monomer methyl methacrylate (MMA) $(m / z=100 \mathrm{Da})$ and $\beta$-CD fragment $\mathrm{C}_{2} \mathrm{H}_{4} \mathrm{O}_{2}(\mathrm{~m} / z=60 \mathrm{Da})$, and the molecular ions of aniline, styrene and toluene having $m / z$ values of 93, 104 and 92, respectively, were investigated (Figs. 6-8). Unfortunately, weak peaks at 92 and $93 \mathrm{Da}$ due to the $\mathrm{C}_{3} \mathrm{H}_{8} \mathrm{O}_{3}$ and $\mathrm{C}_{3} \mathrm{H}_{9} \mathrm{O}_{3}$ fragments are also present in the pyrolysis mass spectra of $\beta-C D$. Thus, the trends in the evolution profiles, i.e. shifts in peak maxima and variations in intensities, have significant importance in the investigation of the evolution of toluene and aniline in the temperature region where $\beta-C D$ based products are generated.

The evolution profiles of MMA for all the samples under investigation showed almost identical trends (Figs. 6-8). The thermal degradation of PMMA occurred above $300^{\circ} \mathrm{C}$, and maximum product yield was detected around $390^{\circ} \mathrm{C}$ yielding mainly the monomer in accordance with previous results in the literature [26-27]. Sim- 


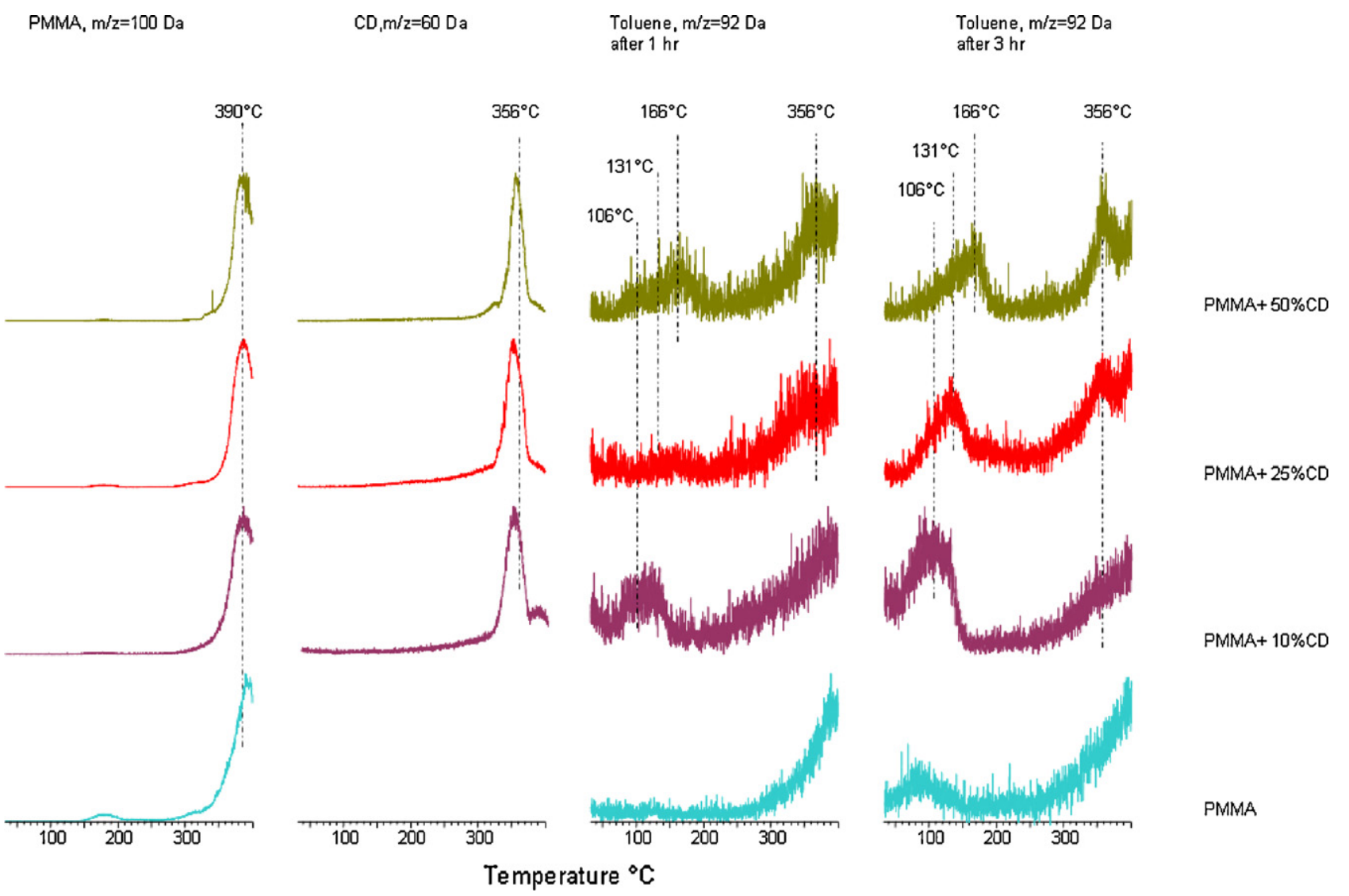

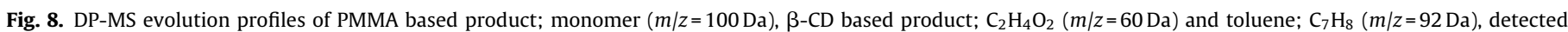

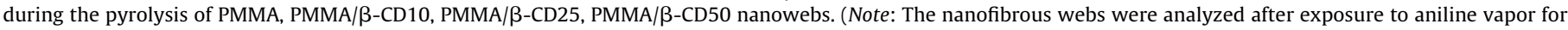
$1 \mathrm{~h}$ and $3 \mathrm{~h}$ ).

ilarly, the evolution profiles of $\beta-C D$ based products also showed identical trends during the pyrolysis of all the PMMA nanofibers containing variable amounts of $\beta-C D$ exposed to saturated aniline, styrene or toluene vapors for 1 or $3 \mathrm{~h}$. Thus, it can be concluded that thermal behaviors of PMMA and $\beta-C D$ were not affected during the trapping processes of organic vapors.

Inspection of the evolution profiles of aniline indicated that trapping of aniline vapor depends both on the amount of $\beta-C D$ present in the PMMA nanofibers and on the time period of exposure. As seen in Fig. 6, no indication of evolution of adsorbed aniline was observed for PMMA nanoweb exposed to aniline vapor for a period of $1 \mathrm{~h}$. The immediate evolution of aniline below $90^{\circ} \mathrm{C}$ during the pyrolysis of the PMMA nanoweb left under the same conditions for an additional $2 \mathrm{~h}$ indicated that adsorption of aniline was quite low, and the adsorption of aniline was most probably due to a very weak interaction between aniline and PMMA nanofibers. This finding suggests that PMMA nanowebs without $\beta-C D$ have no capability of trapping aniline vapor.

In the case of PMMA/ $\beta-C D$ nanowebs, the extent of absorption was also quite low for the PMMA/ $\beta-C D 10$ nanowebs. However, during the pyrolysis of the sample exposed to aniline vapor for a total period of $3 \mathrm{~h}$, the evolution of aniline continued up to $\sim 150^{\circ} \mathrm{C}$. On the other hand, for PMMA $/ \beta-C D 25$ and PMMA $/ \beta-C D 50$ nanowebs, a single and broad peak with a maximum at $\sim 145$ and $\sim 170^{\circ} \mathrm{C}$, respectively, appeared in the single ion pyrogram of aniline. The presence of aniline and its release at high temperatures from PMMA/ $\beta-C D$ nanowebs confirms that PMMA nanowebs containing $\beta$-CD can trap organic vapor from the environment by inclusion complexation. Furthermore, the aniline/MMA peak intensity ratio increased about 1.6 times as the $\beta-C D$ in the sample increased from
$25 \%$ to $50 \%$. Thus, it can be concluded that the amount of aniline trapped increased as the \% weight of $\beta-C D$ in the PMMA nanoweb increased. An increase in the extent of trapping of aniline was also observed as the exposure period was increased from 1 to $3 \mathrm{~h}$. For PMMA $/ \beta-C D 25$ and PMMA/ $\beta-C D 50$ nanowebs, the evolution profiles of aniline also showed a very weak high temperature peak with a maximum at around $358^{\circ} \mathrm{C}$, corresponding to the temperature at which $\beta-C D$ based product yields were maximized. However, unlike the low temperature peak, no noticeable increase in its relative intensity was observed with the increase in exposure period. Thus, its existence was attributed mainly to the evolution of a $\beta-C D$ based product; $\mathrm{C}_{3} \mathrm{H}_{9} \mathrm{O}_{3}$.

Pyrolysis mass spectrometry data indicated that the evolution of styrene from the nanowebs exposed to styrene vapor depends on both the amount of $\beta-C D$ present in the PMMA nanowebs and on the exposure period (Fig. 7). The evolution of styrene was not detected during the pyrolysis of the PMMA nanoweb without $\beta-C D$, indicating that the PMMA nanoweb cannot trap styrene vapor. In the case of PMMA nanofibers containing $10 \% \beta-C D$, again, styrene was not detected after $1 \mathrm{~h}$ of exposure. However, upon increasing the exposure period to $3 \mathrm{~h}$, a weak peak at around $130^{\circ} \mathrm{C}$ appeared in the evolution profile of styrene for the PMMA/ $\beta-C D 10$ nanoweb. The same peak, still quite small, was observed during the pyrolysis of the PMMA/ $\beta-C D 25$ nanoweb indicating that the entrapment of styrene from the surroundings has occurred. The relative intensity of this peak increased significantly for the PMMA/ $\beta-C D 50$ nanoweb. Moreover, the peak maximum was shifted to $160^{\circ} \mathrm{C}$. Additionally, the evolution profiles of styrene detected during the pyrolysis of the PMMA/ $\beta-C D 25$ nanoweb exposed to styrene vapor for $3 \mathrm{~h}$ and the PMMA/ $\beta$-CD50 nanoweb exposed to styrene vapor 
for 1 or $3 \mathrm{~h}$ revealed a second peak with a maximum at around $360^{\circ} \mathrm{C}$ as in the case of aniline evolution profiles. However, the 104 Da peak was absent in the pyrolysis mass spectra of pure $\beta-C D$. Thus, this peak was readily attributed to styrene evolution. Furthermore, for PMMA/ $\beta$-CD50 nanowebs exposed to styrene vapor for $3 \mathrm{~h}$, a third peak with maximum at around $329^{\circ} \mathrm{C}$ appeared in the evolution profile of styrene. A careful study of the evolution profiles in this region revealed the presence of a shoulder in this range for all PMMA nanowebs containing $25 \%$ or $50 \% \beta-C D$. Such high temperature evolution of styrene can only be explained by the formation of an inclusion complex of styrene and $\beta-C D$. Once styrene is included in the $\beta-C D$ cavity, its evolution is hindered until the temperatures where $\mathrm{CD}$ evolution/decomposition takes place. Thus, it can be concluded that as a result of inclusion complexation and the presence of different interactions between styrene and the CD cavity, removal of styrene vapor from the environment has taken place, and its release only achieved at high temperatures.

The evolution of toluene was not observed during the pyrolysis of the PMMA nanoweb exposed to toluene vapor for only $1 \mathrm{~h}$, yet, evolution of toluene was revealed at low temperature (below $100^{\circ} \mathrm{C}$ ) for the PMMA nanoweb exposed to toluene vapor for $3 \mathrm{~h}$, indicating that toluene was adsorbed on the PMMA nanowebs during the longer exposure period (Fig. 8). In the case of the PMMA $\beta-C D$ nanowebs, the evolution of toluene was observed in two regions, indicating the presence of different types of interactions between toluene and $\beta-C D$. The relative intensity of the low temperature peak in the evolution profiles of toluene increased as the exposure period increased from 1 to $3 \mathrm{~h}$, and the peak maximum shifted slightly to higher temperatures as the percent of $\beta-C D$ present in the PMMA nanofiber increased. The peak maxima appeared at $106^{\circ} \mathrm{C}, 131^{\circ} \mathrm{C}$ and $166^{\circ} \mathrm{C}$ for the PMMA/ $\beta$ CD10, PMMA $/ \beta-C D 25$ and PMMA $/ \beta-C D 50$ nanowebs, respectively. A high temperature peak for PMMA/ $\beta-C D 25$ and PMMA $/ \beta-C D 50$ and a shoulder for PMMA/ $\beta$-CD10 nanowebs exposed to toluene vapor for $3 \mathrm{~h}$ were observed at around $356^{\circ} \mathrm{C}$ corresponding to the temperature at which the yields of $\beta-C D$ based products were at maximum. The high temperature peak can readily be attributed to the evolution of a $\beta-\mathrm{CD}$ based product $\mathrm{C}_{3} \mathrm{H}_{8} \mathrm{O}_{3}$ as in case of aniline. However, for this case, its relative intensity was increased with the increase of exposure period of toluene vapor. If it was only due to $\beta-C D$ based products its relative intensity should be independent of the exposure period. Thus, it can be concluded that its existence was due to the evolution of both a $\beta-C D$ fragment and toluene, indicating the formation of an inclusion complex between toluene and $\beta-\mathrm{CD}$. In brief, the pyrolysis mass spectrometry results clearly revealed that PMMA/ $\beta-C D$ nanowebs can trap organic waste vapors such as aniline, styrene and toluene from the environment. In addition, the extent of complexation between $\mathrm{CD}$ and organic vapor increases with an increase in exposure period and an amount of $C D$ present in the nanowebs.

\section{Conclusion}

We have produced $\beta$-cyclodextrin $(\beta-C D)$ functionalized electrospun PMMA nanowebs (PMMA/ $\beta-C D$ ) with the goal of developing functional nanowebs, and we have shown that these PMMA/ $\beta-C D$ nanowebs entrap organic waste vapors such as aniline, styrene and toluene from the environment. The entrapment of such organic waste vapors by PMMA/ $\beta-C D$ nanowebs and their release at high temperature is due to inclusion complexation with $\beta-C D$ that is present on the nanofiber surface. Our findings show a very promising and interesting potential application for the use of cyclodextrin containing electrospun nanofibers/nanowebs as molecular filters and/or nanofilters for the removal of organic waste vapors from the environment.

\section{Acknowledgments}

We gratefully acknowledge the funding to the current project NanoNonwovens from The Danish Advanced Technology Foundation, the collaboration with Fibertex A/S, and the Danish Research Agency for the funding to the iNANO center. State Planning Organization of Turkey (DPT) is acknowledged for the support of UNAM-Institute of Materials Science and Nanotechnology through the National Nanotechnology Research Center Project. Dr. Tamer Uyar acknowledges EU FP7-PEOPLE-2009-RG Marie Curie International Reintegration Grant (IRG) for funding NANOWEB (PIRG06-GA-2009-256428) project. We thank to Asli Celebioglu for the SEM imaging of the nanowebs after exposure to organic vapors.

\section{References}

[1] A. Greiner, J.H. Wendorff, Electrospinning: a fascinating method for the preparation of ultrathin fibers, Angew. Chem. Int. Ed. 46 (2007) 56705703.

[2] S. Agarwal, J.H. Wendorff, A. Greiner, Chemistry on electrospun polymeric nanofibers: merely routine chemistry or a real challenge? Macromol. Rapid Commun. 31 (2010) 1317-1331.

[3] S. Ramakrishna, K. Fujihara, W.-E. Teo, T. Yong, Z. Ma, R. Ramaseshan, Electrospun nanofibers: solving global issues, Mater. Today 9 (2006) 4050.

[4] X. Lu, C. Wang, Y. Wei, One-dimensional composite nanomaterials: synthesis by electrospinning and their applications, Small 5 (2009) 2349-2370.

[5] R.S. Barhate, S. Ramakrishna, Nanofibrous filtering media: filtration problems and solutions from tiny materials, J. Membr. Sci. 296 (2007) 1-8.

[6] R.S. Barhate, C.K. Loong, S. Ramakrishna, Preparation and characterization of nanofibrous filtering media, J. Membr. Sci. 283 (2006) 209218.

[7] T.Uyar, R. Havelund, Y. Nur, J. Hacaloglu, F. Besenbacher, P. Kingshott, Molecular filters based on cyclodextrin functionalized electrospun fibers, J. Membr. Sci. 332 (2009) 129-137.

[8] A. Patanaik, V. Jacobs, R.D. Anandjiwala, Performance evaluation of electrospun nanofibrous membrane, J. Membr. Sci. 352 (2010) 136-142.

[9] J. Szejtli, Introduction and general overview of cyclodextrin chemistry, Chem. Rev. 98 (1998) 1743-1753.

[10] E.M.M. Del Valle, Cyclodextrins and their uses: a review, Process Biochem. 39 (2004) 1033-1046

[11] M.V. Rekharsky, Y. Inoue, Complexation thermodynamics of cyclodextrins, Chem. Rev. 98 (1998) 1875-1917.

[12] K.A. Connors, The stability of cyclodextrin complexes in solution, Chem. Rev. 97 (1997) 1325-1357.

[13] L. Szente, E. Fenyvesi, J. Szejtli, Entrapment of iodine with cyclodextrins: potential application of cyclodextrins in nuclear waste management, Environ. Sci. Technol. 33 (1999) 4495-4498.

[14] G. Crini, M. Morcellet, Synthesis and applications of adsorbents containing cyclodextrins, J. Sep. Sci. 25 (2002) 789-813.

[15] J. Olah, T. Cserhati, J. Szejtli, $\beta$-Cyclodextrin enhanced biological detoxification of industrial waste waters, Water Res. 22 (1988) 1345-1351.

[16] T. Uyar, M.A. Hunt, H.S. Gracz, A.E. Tonelli, Crystalline cyclodextrin inclusion compounds formed with aromatic guests: guest-dependent stoichiometries and hydration-sensitive crystal structures, Cryst. Growth Des. 6 (2006) 1113-1119.

[17] S. Kaur, M. Kotaki, Z. Ma, R. Gopal, S. Ramakrishna, Oligosaccharide functionalized nanofibrous membrane, Int. J. Nanosci. 5 (2006) 1-11.

[18] T. Uyar, R. Havelund, J. Hacaloglu, F. Besenbacher, P. Kingshott, Functiona electrospun polystyrene nanofibers incorporating alpha, beta and gamma cyclodextrins: comparison of molecular filter performance, ACS Nano (2010). doi:10.1021/nn100954z.

[19] T. Uyar, A. Balan, L. Toppare, F. Besenbacher, Electrospinning of cyclodextrin functionalized poly(methyl methacrylate)(PMMA) nanofibers, Polymer 50 (2009) 475-480.

[20] L. Rabara, M. Aranyosiova, D. Velic, Supramolecular host-guest complexes based on cyclodextrin-diphenylhexatriene, Appl. Surf. Sci. 252 (2006) 7000-7002.

[21] T. Uyar, R. Havelund, J. Hacaloglu, X. Zhou, F. Besenbacher, P. Kingshott, Formation and characterization of cyclodextrin functionalized polystyrene nanofibers produced by electrospinning, Nanotechnology 20 (2009) 125605-125618.

[22] T. Uyar, A. El-Shafei, X. Wang, J. Hacaloglu, A.E. Tonelli, The solid channel structure inclusion complex formed between guest styrene and host gamma-cyclodextrin, J. Incl. Phenom. Macrocycle Chem. 55 (2006) 109121.

[23] T. Uyar, A.E. Tonelli, J. Hacaloglu, Thermal degradation of polycarbonate, poly(vinyl acetate) and their blends, Polym. Degrad. Stab. 91 (2006) 2960-2967. 
[24] T. Uyar, C.C. Rusa, A.E. Tonelli, J. Hacaloglu, Pyrolysis mass spectrometry analysis of polycarbonate/poly(methyl methacrylate)/poly(vinyl acetate) ternary blends, Polym. Degrad. Stab. 92 (2007) 32-43.

[25] T. Uyar, L. Toppare, J. Hacaloglu, Thermal and structural characterization of polypyrrole by direct-insertion probe pyrolysis mass spectrometry, Synth. Met. 119 (2001) 307-308.
[26] G. Montaudo, C. Puglisi, F.J. Samperi, Chemical reactions occurring in the thermal treatment of PC/PMMA blends, J. Polym. Sci. Part A: Polym. Chem. 36 (1998) 1873-1884.

[27] M. Ferriol, A. Gentilhomme, M. Cochez, N. Oget, J.L. Mieloszynski, Thermal degradation of poly(methyl methacrylate) (PMMA): modelling of DTG and TG curves, Polym. Degrad. Stab. 79 (2003) 271-281. 